\title{
ASSESSMENT OF THE ANTI-DIARRHEA FUNCTION OF COMPOUND CHINESE HERBAL MEDICINE CANGPO ORAL LIQUID
}

\section{Xinchao Xia ${ }^{1 \#}$, Hui Wang ${ }^{1 \#}$, Xu Niu ${ }^{3}$, Haijun Wang ${ }^{1}$, Zhiqi Liu ${ }^{2}$, Yongming Liu ${ }^{1}$, Zhiming Qi $^{1}$, Shengyi Wang ${ }^{1}$, Shixiang Liu ${ }^{1}$, and Shanshan $\mathrm{Liu}^{4}$}

${ }^{1}$ Key Laboratory of Veterinary Pharmaceutics Discovery, Ministry of Agriculture, Engineering \& Technology Research Center of Traditional Chinese Veterinary Medicine of Gansu Province, Lanzhou Institute of Animal Science and Veterinary Pharmaceutics, Chinese Academy of Agricultural Sciences, Lanzhou 730050, Gansu, China; ${ }^{2}$ Institute of Agro-Products Processing Science and Technology, Chinese Academy of Agricultural Sciences, Beijing 100193, China; ${ }^{3}$ Faculté de Médecine, Université de Bretagne Occidentale, 29238 Brest, France;

${ }^{4}$ Lanzhou Productivity Promoting Center, Lanzhou 730030. China

*E-mail: myslym@sina.com,wanghui01@ caas.cn

${ }^{\#}$ Contributed equally.

\begin{abstract}
Background: Diarrhea is a big problem in piglets. Cangpo Oral Liquid (COL) is a compound of Chinese herbal medicine. The preparation was fed to piglets had diarrheal disease in order to determine its anti-diarrhea activity and potential applications in vivo.

Materials and Methods: The contents of Berberine hydrochloride, Magnolol and Honokiol in COL were performed on HPLC analysis. Organ bath was used to investigate the effect of COL on peristaltic reflexes and peristaltic waves in vitro. And anti-diarrhea activity of COL was evaluated in clinical.

Results: Thin layer chromatography (TLC) and HPLC analyses showed that the contents of Berberine hydrochloride, Magnolol and Honokiol in COL were $970 \mu \mathrm{g} / \mathrm{mL}, 130 \mu \mathrm{g} / \mathrm{mL}$ and $300 \mu \mathrm{g} / \mathrm{mL}$, respectively. Administration of the COL to the organ bath caused a concentration-dependent inhibition of intestinal peristalsis. When the COL concentration in the bath was cumulatively increased, the amplitude and frequency of the peristaltic waves was lowered. The result of clinical efficacy of COL was very effective to diarrheic piglets. COL can possibly inhibit the curve of peristaltic waves in vitro; and clinical trial showed a statistically significant therapeutic effect in vivo.

Conclusion: In conclusion, COL can be used as an effective therapeutic agent. However, the ingredients, pharmacokinetics and specific signaling pathways of COL need to be further studied.
\end{abstract}

Key words: Cangpo Oral Liquid, therapeutic effect, peristalsis, herbal

\section{Introduction}

Diarrhea in piglets cansed by Enterobacteria is a big problem in many farms. Diarrhea in piglets is not only causing an economic loss, but also decreases growth rates, and easily causes second infection. The causes of piglet diarrhea are multi-factored. The typical cause is the hostenvironment-pathogen interactions (Dewey et al., 1995). Piglet diarrhea may be associated with various enteric pathogens. These agents include: enterotoxigenic Escherichia coli, Clostridium perfringens type C, transmissible gastroenteritis virus (TGE), porcine epidemic diarrhea virus (PEDV), etc. Although usually there is one primary causative agent, piglets can have mixed infections. This disease leads to significant morbidity, and mortality in neonatal piglets (Jung et al., 2008). Although there are different kinds of commercial antibiotics available for use in the prevention, and treatment of piglets diarrhea; its contribution to the problem of antibiotic residues and/or antimicrobial resistance, to the treatment and prevention of piglet diarrhea is still important and necessary.

Traditional Chinese Medicine (TCM), is a medical system in China that has been used for thousands of years to diagnose and treat diseases (Chou et al., 2008). TCM theories are based on syndrome differentiation and holistic medicine. Chinese herbal medicine (CHM) is a pharmaceutical part and the most important component of the TCM system, which has long been used for its multiple combinations of compounds in the form of processed natural products (Li and Peng, 2013), with extensive literature and clinical applications covering thousands of years (Xu and Yang, 2009). A compound formulation is prescribed according to the principle, "Monarch, Minister, Assistant and Guide." A formulation that contains $\geq 2$, Chinese herbs better conforms to TCM, theories and better reflects the characteristics of TCM than the administration of a single herb (Jiao, 2004). Investigations into the effects of CHM formulas are now attracting increasing attention around the world (Shi et al., 2011).

Cangpo Oral Liquid (COL), a compound of CHM, consists of 9, crude drugs: Rhizoma Atractylodis, Cortex Magnoliae Officinalis, Rhizoma Coptidis, Pericarpium Citri Reticulatae, Semen Myristicae, Fructus Mume, Fructus Psoraleae, Poria cocos and Semen Lablab Album. According to the TCM theory, Cortex Magnoliae Officinalis is the chief component in this prescription, which has been clinically used in China for various diseases such as cough, diarrhea, atherosclerosis, antimicrobial and antioxidant (Chan et al., 2008; Karki et al., 2012). Rhizoma coptidis is well-known and commonly used in TCM, with the efficacy of antiviral activity, anti-inflammatory, anti-diarrhea, antimicrobial activity, etc, in its' extracts (Kong et al., 2009; Dou et al., 2010; Zuo et al., 2012). Rhizoma Atractylodis is a plant material with the main clinical function of anti-diarrhea, anti-fatigue and anti-inflammation and it has been showed to increase immune response under in vivo and in vitro conditions (Prieto et al., 2003; Zhu et al., 2007). Pericarpium Citri Reticulatae, Fructus Mume, Fructus Psoraleae, Poria cocos and Semen Lablab Album have been used traditionally as medicinal herbs for the treatment of gastrointestinal infections in Asia and several research studies revealed that these herbs showed antimicrobial activities against microbial infections in the clinic (Nakajima et al., 2006; Chinese Pharmacopoeia Commission, 2010; Gong et al., 2010; Lu et al., 2010; Chen et al., 2012).

This study is purposed to evaluate the therapeutic potentials of the compounds of COL for their anti-diarrhea property. The preparation was fed to piglets that had diarrheal disease in order to determine its anti-diarrhea activity and potential applications in vivo. 
http://dx.doi.org/10.4314/ajtcam.v11i1.22

\section{Materials and Methods}

Preparation of COL extract

Cangpo Oral Liquid (COL) consists of 9 crude drugs, plant parts and its origin used in the formula as Table 1. Briefly, mixture of 150g of Rhizoma Atractylodis, 90g of Cortex agnoliae Officinalis, 90g of Rhizoma Coptidis, 100g of Pericarpium Citri Reticulatae, 130g of Semen Myristicae, 150g of Fructus Mume, 100g of Fructus Psoraleae, 90g of Poria cocos and 100g of Semen Lablab Album was macerated for 3hrs, with $14000 \mathrm{~mL}$ of distilled water, and decocted in $100{ }^{\circ} \mathrm{C}$ for $1.5 \mathrm{hrs}$, after which the filtrate was collected, and the residue was decocted again for $1.5 \mathrm{rs}$ with $8000 \mathrm{~mL}$ of distilled water. The extracts were combined, and further condensed at $65{ }^{\circ} \mathrm{C}$, the aqueous extract of $\mathrm{COL}(1000 \mathrm{~mL})$, was obtained.

Table 1. The composition of COL

\begin{tabular}{llllll}
\hline Species & Chinese name & Plant part & Origin & Grams, g & $\%$ \\
\hline Rhizoma Atractylodis & Cang zhu & Root, stem & Inner Mongolia, China & 150 & 15 \\
Cortex Magnoliae Officinalis & Hou po & Root bark & Shaanxi, China & 90 & 9 \\
Rhizoma Coptidis & Huang lian & Root & Sichuan, China & 90 & 9 \\
$\begin{array}{l}\text { Pericarpium Citri Reticulatae } \\
\text { Semen Myristicae }\end{array}$ & Rou pi & Fruit peel & Hubei, China & 100 & 10 \\
Fructus Mume & Wu mei & Fruit & Guangxi, China & 130 & 13 \\
Fructus Psoraleae & Bu gu zhi & Fruit & Shaanxi, China & 150 & 15 \\
$\begin{array}{l}\text { Poria cocos } \\
\text { Semen Lablab Album }\end{array}$ & Fu ling & Sclerotium & Anhui, China & 90 & 10 \\
Total amount & Bai bian dou & Fruit & Liaoning, China & 100 & 10 \\
\hline
\end{tabular}

Chemical component analysis of COL

Thin layer chromatography (TLC), analysis of COL.

$2 \mathrm{~mL}$ COL, was dissolved in $20 \mathrm{~mL}$ methanol, the filtrate was collected and spotted on the silica gel-CMC plate (Qindao Haiyang Chemical Reagent Factory, China), with $5 \mu \mathrm{L}$, and benzene-ethyl acetate-methanol-isopropyl alcohol-strong ammonia solution (12:6:3:3:1), was used as the developing solvent to develop it. The methanol solution of Rhizoma Coptidis and Berberine hydrochloride used as standard preparation. Observing it under the UV light $(365 \mathrm{~nm}) .40 \mathrm{~mL}$ COL, was dissolved in $40 \mathrm{~mL}$ petroleum ether, the petroleum ether extraction was volatilized until dry. After that, the residue was dissolved in $1 \mathrm{~mL}$ ethyl acetate and spotted on the silica gel-CMC plate with $10 \mu \mathrm{L}$, and cyclohexane-dichloromethane-ethyl acetate-strong ammonia solution (5:2:4:0.5), was used as the developing solvent. Magnolol and Honokiol used as standard preparation. Observing it under the UV light $(254 \mathrm{~nm})$.

\section{High performance liquid chromatography (HPLC) analysis of COL}

The amount of Berberine hydrochloride, Magnolol and Honokiol in the COL, was analyzed with HPLC (Waters, USA). $1 \mathrm{~mL}$ sample of COL was extracted with methanol $(15 \mathrm{~mL})$, by ultrasonic at room temperature for 30min., then dilute with methanol to $25 \mathrm{~mL}$. Data acquisition and quantification were performed using Millenium 2.10 version software (Waters). Symmetry reversed-phase column $\left(\mathrm{C}_{18}, 250 \mathrm{~mm} \times 4.6 \mathrm{~mm}\right.$; particle size $5 \mu \mathrm{m}$, Waters, USA), was maintained at $30^{\circ} \mathrm{C}$. The mobile phase was filtered through a Millipore $0.45 \mu \mathrm{m}$ filter and degassed prior to use.

Berberine hydrochloride: The mobile phase was a mixture of acetonitrile-water (47:53), pumped in isocratic mode with a flow rate of $1 \mathrm{~mL} / \mathrm{min}$. The mobile phase was filtered through a Millipore $0.45 \mu \mathrm{m}$ filter and degassed prior to use. The peaks were detected at $347 \mathrm{~nm}$.

Magnolol and Honokiol: The mobile phase was a mixture of methanol-water-acetonitrile (50:20:30), the flow rate was $1 \mathrm{~mL} / \mathrm{min}$. The peaks were detected at $294 \mathrm{~nm}$. Berberine hydrochloride, Magnolol and Honokiol were detected by comparing with the corresponding chemical marks, which were identified with nuclear magnetic resonance (NMR) (Figure 1).

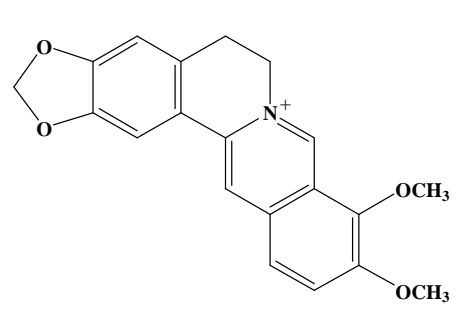

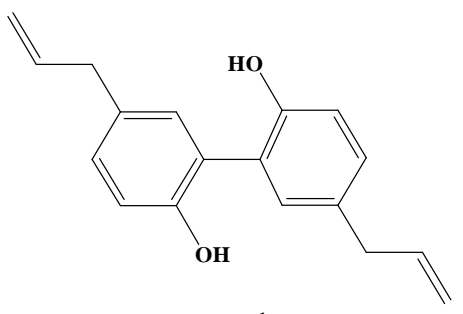

1

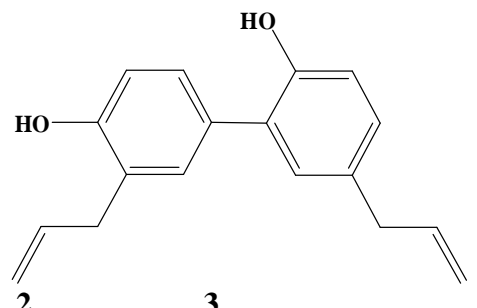

3

Figure 1: The chemical structures of Berberine hydrochloride (1), Magnolol (2), and Honokiol (3).

\section{Effects of COL on small intestine peristalsis of piglet in vitro}

Piglet of either sex, weighing between 400 and $500 \mathrm{~g}$ were killed by a blow to the occipital region of the head and severing the carotid arteries. The small intestine (jejunum and ileum) was isolated, flushed of luminal contents and placed, for up to 4hrs, in Tyrode's solution (pH 7.4, $\mathrm{NaCl} 136.9 \mathrm{mM}, \mathrm{KCl} 2.7 \mathrm{mM}, \mathrm{CaCl}_{2} 1.8 \mathrm{mM}, \mathrm{MgCl}_{2} 1.0 \mathrm{mM}, \mathrm{NaHCO}_{3} 11.9 \mathrm{mM}, \mathrm{NaH}_{2} \mathrm{PO}_{4} 0.4 \mathrm{mM}$ and glucose $\left.5.6 \mathrm{mM}\right), \mathrm{kept}$ at $37^{\circ} \mathrm{C}$, and oxygenated with a mixture of $95 \% \mathrm{O}_{2}$ and $5 \% \mathrm{CO}_{2}$ (Heinemann et al., 1999). To pharmacologically isolate certain regions of the small intestine, the partitioned organ bath technique was used. This technique allows the selective addition of drugs to specific neural components active during orally and anally directed reflexes (Ji et al., 2004). The small intestine was divided into eight segments, each being approximately $10 \mathrm{~cm}$ long. Four intestinal segments were set up in parallel and secured horizontally in organ baths containing 30mL of Tyrode's solution at 37 ${ }^{\circ} \mathrm{C}$. The preparations were allowed to equilibrate in the organ bath for a period of $60 \mathrm{~min}$. Each segment was exposed to only one drug 
http://dx.doi.org/10.4314/ajtcam.v11i1.22

concentration. Each drug concentration was allowed to equilibrate for 30min., before further reflex responses were elicited, because drug effects usually became maximal within 30min., (Herbert et al., 2005). The effects of drugs on the mechanical activity of the circular muscle were assessed by comparing the mean of three responses before and after applications of drugs. The maximal amplitude and the area under the curve of the oral and anal contraction to a mucosal stimulus were obtained for the evaluation of the effects of drugs on peristaltic reflexes. The study was performed in compliance with the Guidelines for the care and use of laboratory animals as described in the US National Institutes of Health.

\section{Evaluation of anti-diarrhea activities of COL}

A total of 264, piglets diarrhea treatment in Tianpeng Aquaculture Co., Ltd., Tianshui, Gansu Province, China were selected for experimental design. The procedure of piglet's diarrhea treatment was shown in Table 2 . Recording the number of piglet recovery, rate of piglet recovery after 3 , days treatment by drugs, the number of piglets relapse and relapse rate.

Table 2: Procedure of piglets diarrhea treatment by COL and antibiotics

\begin{tabular}{lllll}
\hline Drugs & Number of piglet & Dose & Way apply & Duration \\
\hline COL (I) & 33 & $7 \mathrm{~mL} /$ day & p.o. & $1-3$ days \\
COL (II) & 45 & $10 \mathrm{~mL} /$ day & p.o. & $1-3$ days \\
COL (III) & 33 & $15 \mathrm{~mL} /$ day & p.o. & $1-3$ days \\
Ofloxacin (4\%) & 60 & $0.1 \mathrm{~mL} / 1 \mathrm{kgP} /$ day & i.m. & $1-3$ days \\
Norfloxacin (10\%) & 51 & $1 \mathrm{~mL} /$ day & p.o. & $1-3$ days \\
Ofloxacin (4\%)-Norfloxacin (10\%) & 42 & $1 \mathrm{~mL} /$ day & p.o. & $1-3$ days \\
\hline
\end{tabular}

\section{Results}

The contents of Berberine hydrochloride, Magnolol and Honokiol in COL

Rhizoma coptidis and Cortex Magnoliae Officinalis have been proved with anti-diarrhea activity (Chan et al., 2008; Kong et al., 2009; Dou et al., 2010; Karki et al., 2012; Zuo et al., 2012). The contents of Berberine hydrochloride, Magnolol and Honokiol were first investigated in this paper. TLC and HPLC analyses showed that the contents of Berberine hydrochloride, Magnolol, and Honokiol in COL were $970 \mu \mathrm{g} / \mathrm{mL}$, $130 \mu \mathrm{g} / \mathrm{mL}$ and $300 \mu \mathrm{g} / \mathrm{mL}$, respectively (Figures 2, 3, 4 and 5). The anti-diarrhea activity of COL was valuable to study further.

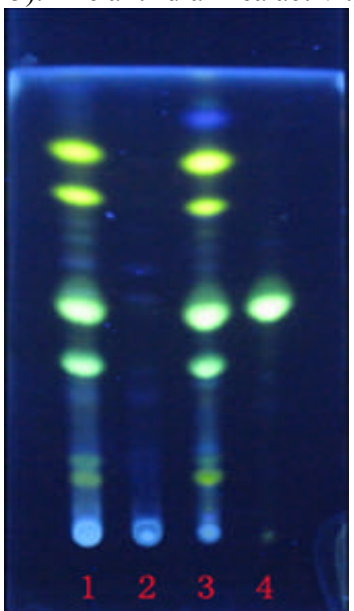

Figure 2: The TLC chromatograms of COL (1), negative control (2), the extract of Rhizoma Coptidis (3), Berberine hydrochloride (4).

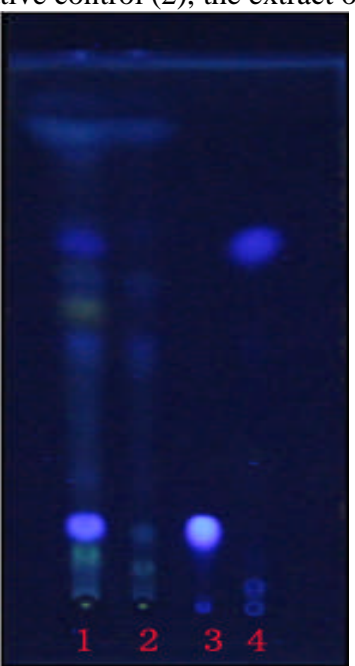

Figure 3: The TLC chromatograms of COL (1), negative control (2), Magnolol (3), and Honokiol (4). 
http://dx.doi.org/10.4314/ajtcam.v11i1.22

A

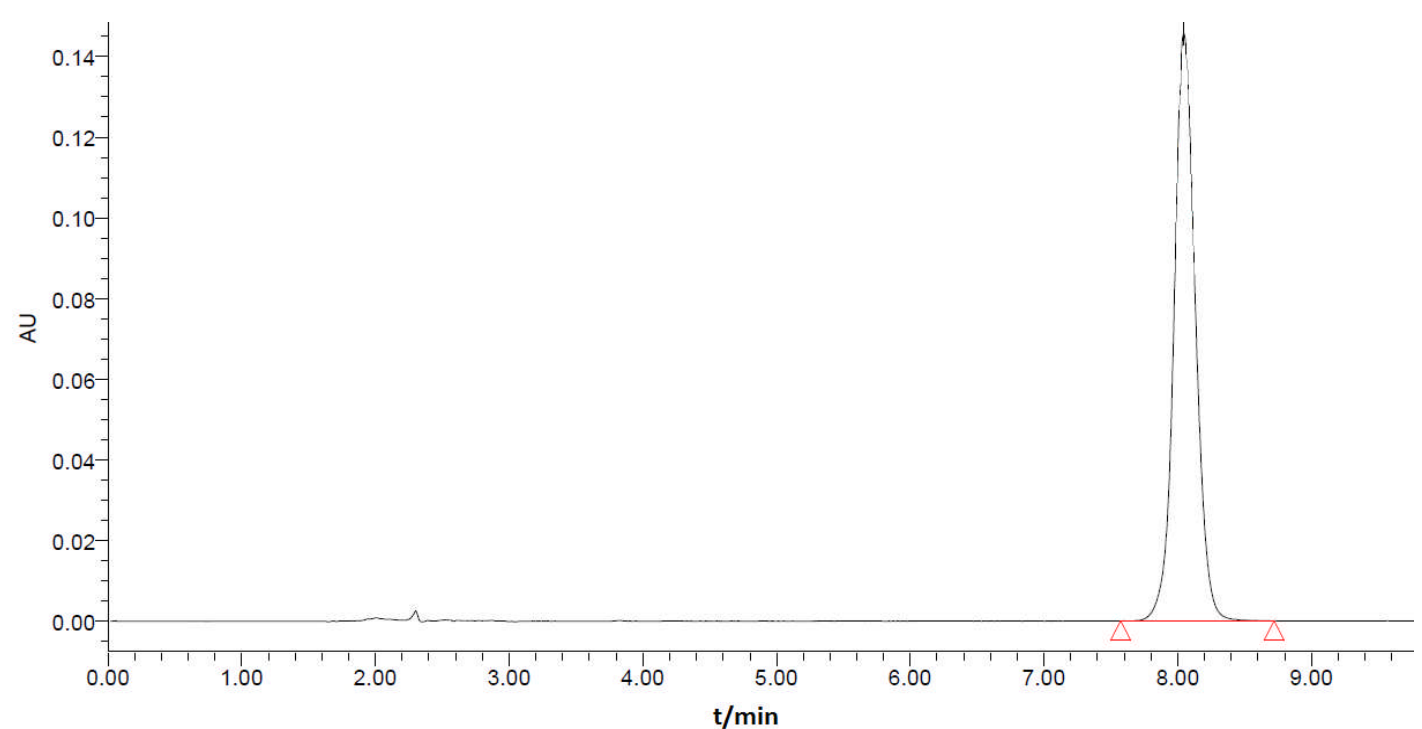

B

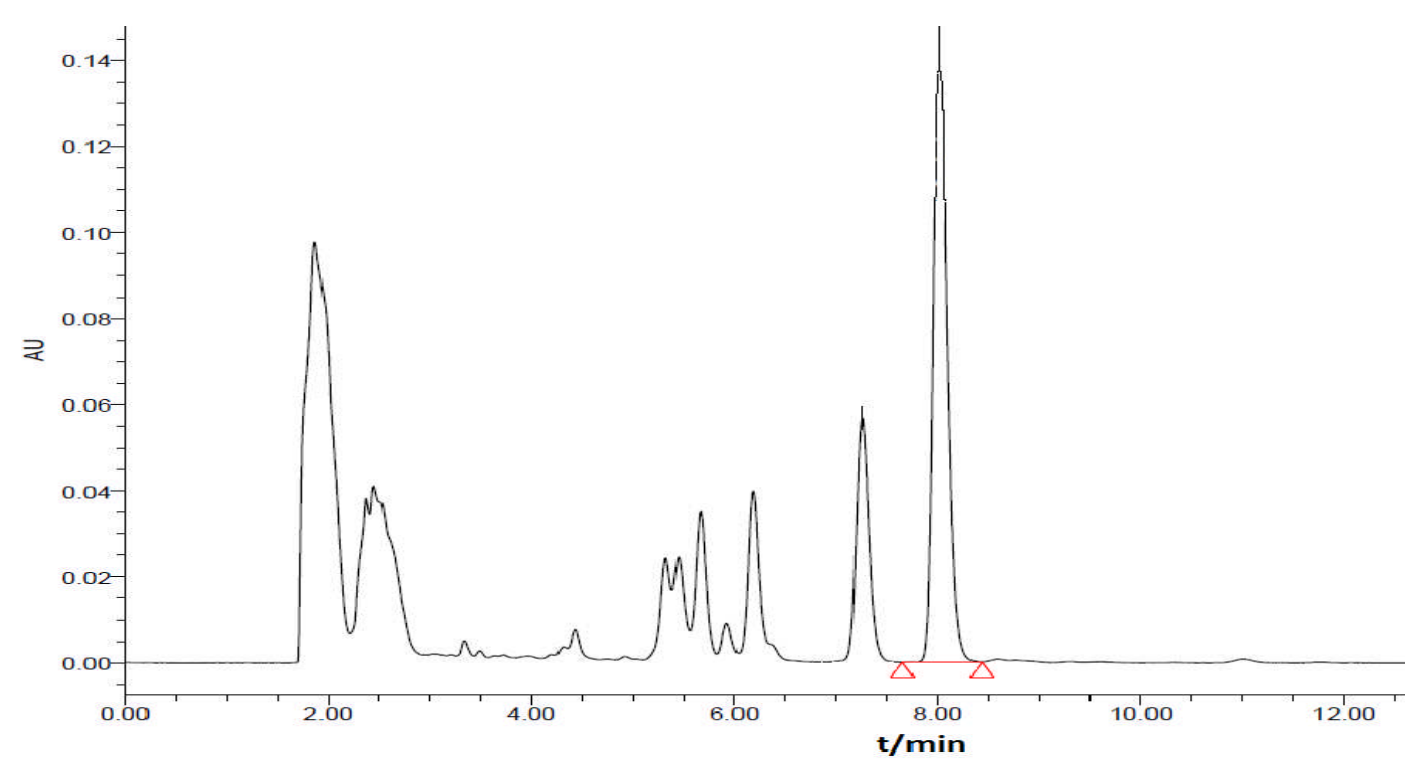

Figure 4: The HPLC chromatograms at $347 \mathrm{~nm}$ of the reference substances (A) and the COL (B).

A

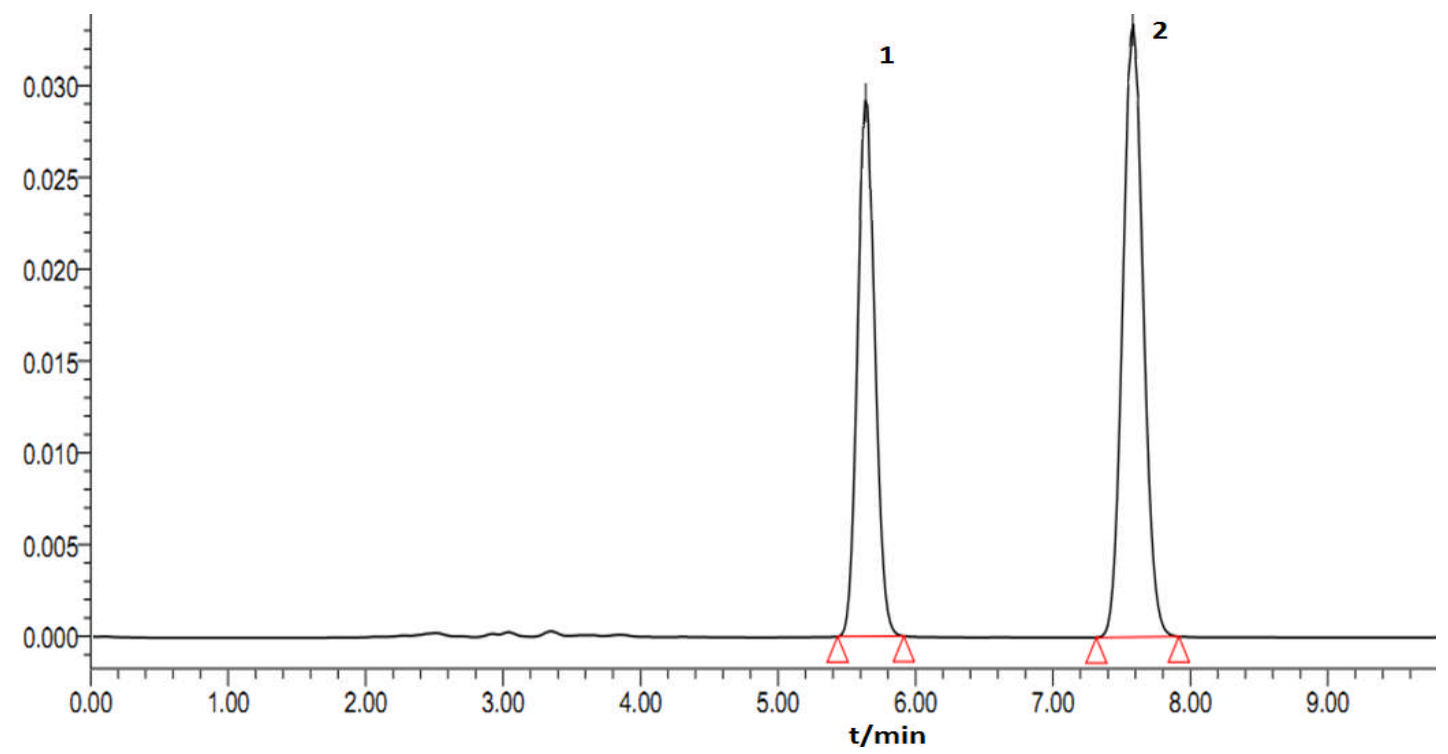


B

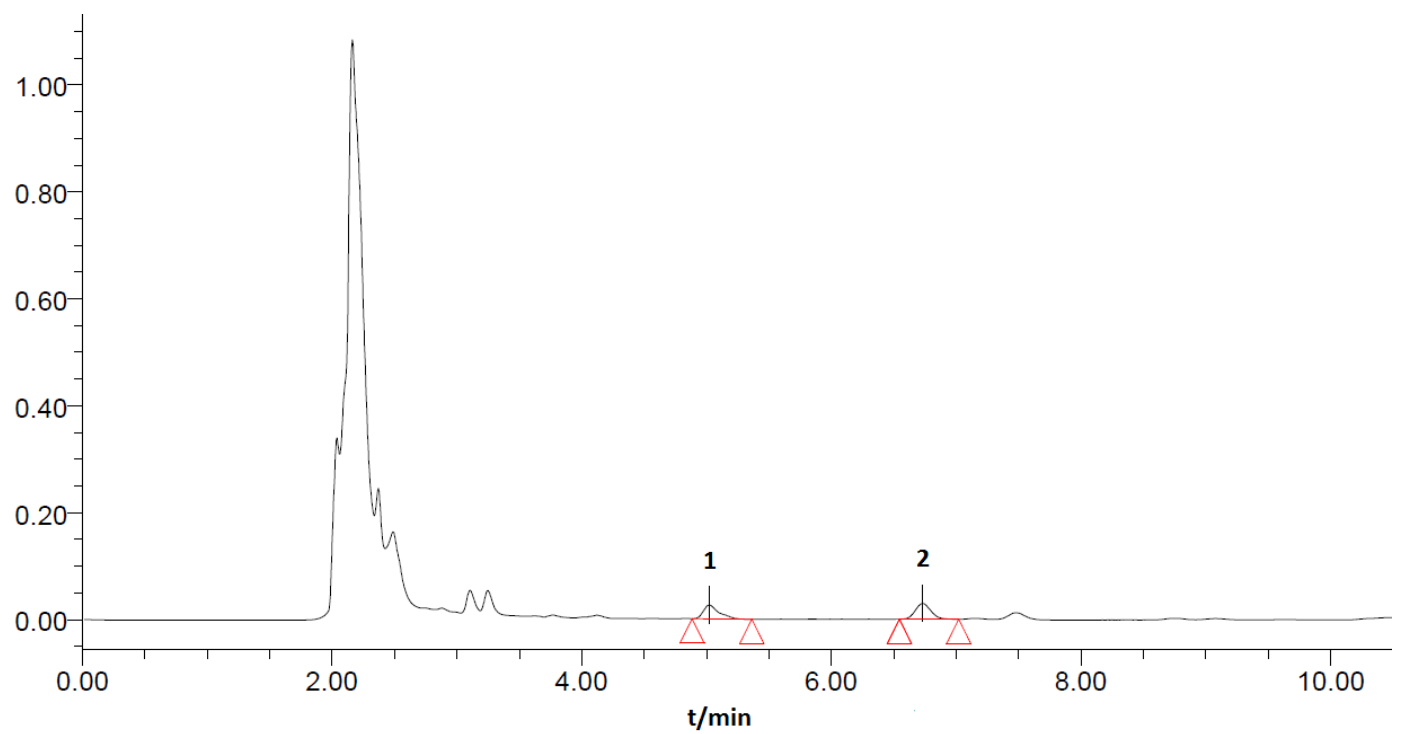

Figure 5: The HPLC chromatograms at $254 \mathrm{~nm}$ of the reference substances (A) and the COL (B). Honokiol (1) and Magnolol (2).

\section{Recordings of the effect of COL on peristalsis}

Administration of the COL to the organ bath caused a concentration-dependent inhibition of intestinal peristalsis (Figure 6). Peristaltic contractions remained constant in all experiments during the control period before any drug administration, and were not influenced by the addition of vehicle (Tyrode's solution, Figure 6A). When the COL concentration in the bath was cumulatively increased, it lowered the amplitude and frequency of the peristaltic waves (Figure 6C and D).

A

B

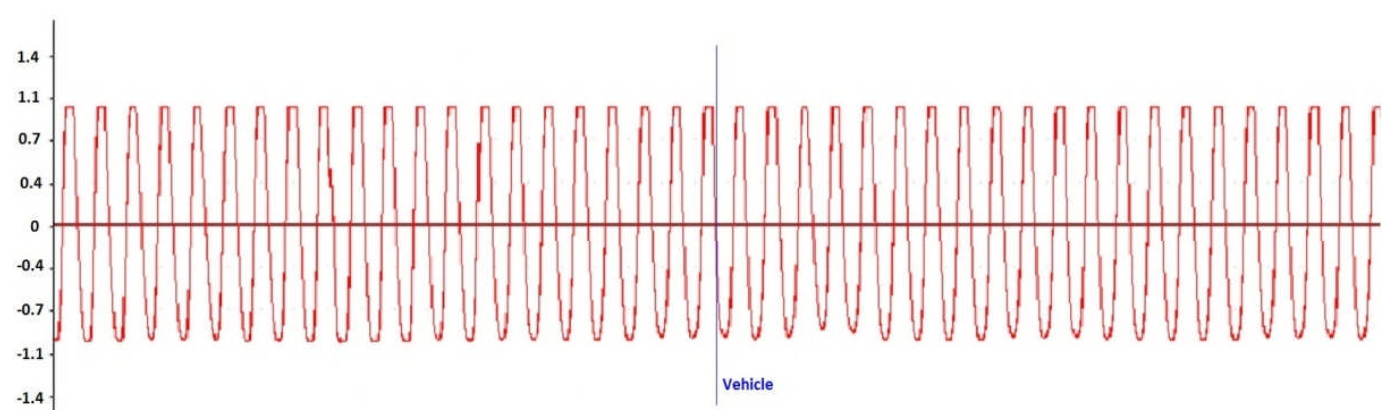

C

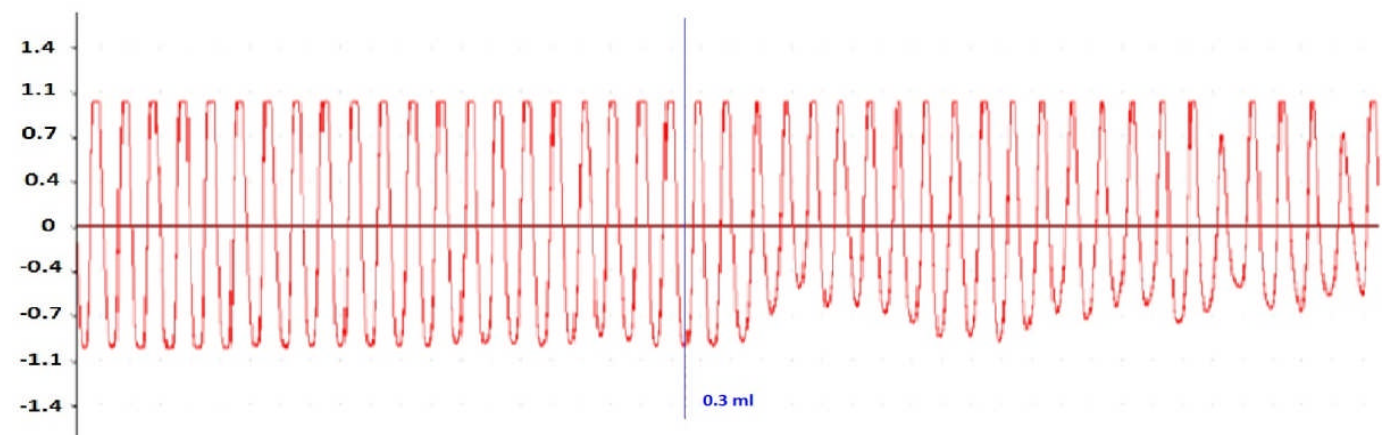




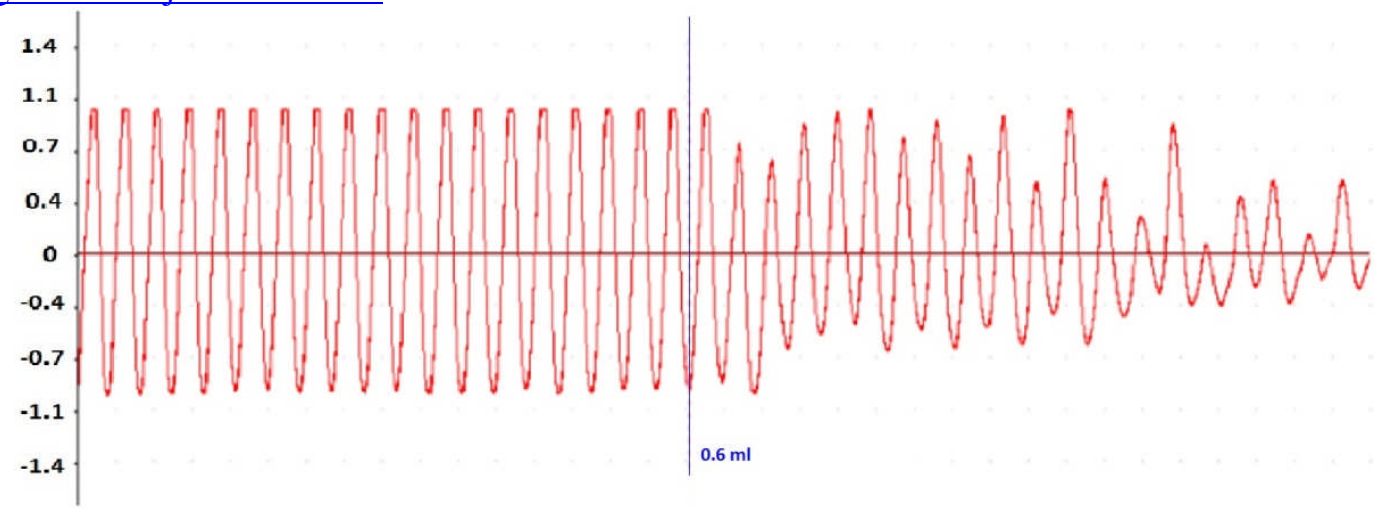

D

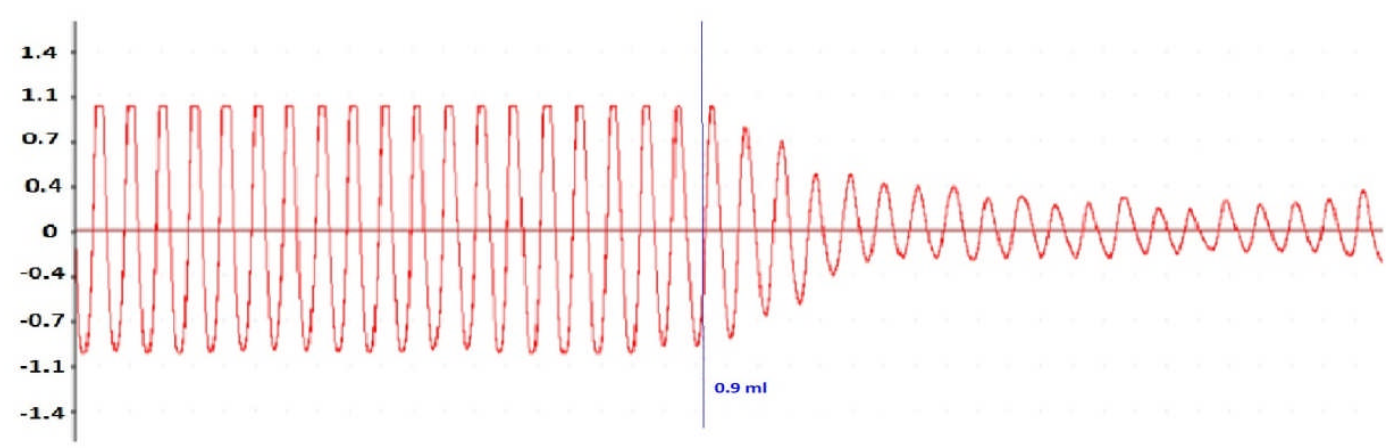

Figure 6: Original recordings of the effect of vehicle and COL $(0.3-0.9 \mathrm{~mL})$, on peristalsis in isolated segments of the piglet small intestine. (A) Peristaltic activity was constant during a control period and remained uninfluenced by vehicle (Tyrode's solution). (B) Addition of $0.3 \mathrm{~mL}$ COL led to a decrease in the number of peristaltic waves, whereas $(\mathrm{C})$ a larger concentration of $\mathrm{COL}(0.6 \mathrm{~mL})$ caused irregularity and decreased the number of peristaltic waves. (D) COL at $0.9 \mathrm{~mL}$ significantly decreased the number and the area under the curve of peristaltic waves.

\section{Effects of COL on piglets diarrhea in vivo}

The result of treatment piglets diarrhea using COL and antibiotics was presented in Table 3. The study showed that the cure rate of COL (7mL/day), was very effective to diarrheic piglets in Tianpeng Aquaculture Co., Ltd. And Ofloxacin (4\%)-Norfloxacin (10\%), was moderately sensitive to diarrhea. The cure rate was COL (II) $>$ COL (III) $>$ Ofloxacin (4\%)-Norfloxacin $(10 \%)>$ COL (I) $>$ Norfloxacin $(10 \%)>$ Ofloxacin $(4 \%)$. The results of chi-square test $\left(\chi^{2}\right)$, for cure rate showed that COL had a higher level than Ofloxacin and Norfloxacin $(\mathrm{P}<0.05)($ Table 4$)$.

Table 3. The result of piglets diarrhea treatment using COL and antibiotics

\begin{tabular}{lllllll}
\hline Drugs & $\begin{array}{l}\text { Number of } \\
\text { cases }\end{array}$ & $\begin{array}{l}\text { Number of } \\
\text { Cure }\end{array}$ & $\begin{array}{l}\text { Cure rate } \\
(\%)\end{array}$ & $\begin{array}{l}\text { Number of } \\
\text { Relapse }\end{array}$ & $\begin{array}{l}\text { Relapse rate } \\
(\%)\end{array}$ & $\begin{array}{l}\text { Average period } \\
\text { of treatment (d) }\end{array}$ \\
\hline COL (I) & 33 & 25 & 75.0 & 1 & 4.0 & 1.54 \\
COL (II) & 45 & 40 & 88.9 & 0 & 0.0 & 1.56 \\
COL (III) & 33 & 27 & 83.3 & 1 & 3.7 & 1.85 \\
Ofloxacin (4\%) & 60 & 41 & 68.3 & 4 & 9.8 & 1.5 \\
Norfloxacin (10\%) & 51 & 35 & 68.6 & 5 & 13.2 & 2.4 \\
Ofloxacin (4\%)- & 42 & 34 & 81.0 & 2 & 5.9 & 2.0 \\
Norfloxacin (10\%) & & & & & & \\
\hline
\end{tabular}

Table 4. The results of chi-square test $\left(\chi^{2}\right)$ for cure rate using different drugs

\begin{tabular}{llll}
\hline Drugs & Ofloxacin & Norfloxacin & Ofloxacin-Norfloxacin \\
\hline COL & $4.770^{*}$ & $4.193^{*}$ & 0.078 \\
Ofloxacin & & 0.01 & 2.021 \\
Norfloxacin & & 1.827 \\
\hline
\end{tabular}

Note: $\chi_{0.05(1)}^{2}=3.841, \chi_{0.01(1)}^{2}=6.635 . *$ means $\mathrm{P}<0.05$, **means $\mathrm{P}<0.01$.

Among these drugs the average period of treatment of COL $(10 \mathrm{~mL} /$ day $)$, was short and the relapse rate was lowest. The relapse rate was Norfloxacin $(10 \%)>$ Ofloxacin (4\%) > Ofloxacin (4\%)-Norfloxacin $(10 \%)>$ COL (I) > COL (III) > COL (II) (Table 3). The results of chi-square test $\left(\chi^{2}\right)$ for relapse rate showed that COL had a significantly lower level than Ofloxacin and Norfloxacin $(\mathrm{P}<0.01)($ Table 5$)$.

Table 5. The results of chi-square test $\left(\chi^{2}\right)$ for relapse rate using different drugs

\begin{tabular}{llll}
\hline Drugs & Ofloxacin & Norfloxacin & Ofloxacin-Norfloxacin \\
\hline COL & 3.785 & $7.142^{* *}$ & 1.111 \\
Ofloxacin & & 0.371 & 0.379 \\
Norfloxacin & & 1.336 \\
\hline
\end{tabular}


http://dx.doi.org/10.4314/ajtcam.v11i1.22

The study showed that the therapeutic effects of COL for treatment of piglet diarrhea better than antibiotics (Ofloxacin and Norfloxacin).

\section{Discussion}

The piglet diarrhea caused great loss to the pig breeding industry. The main clinical measure was the application of antibiotic, but the long term application gave rise to drug resistance of bacteria and low cure rate. Besides, more and more attentions were paid to the toxic and side effects of antibiootic residue ( $\mathrm{Li}$ et al., 2007). The CHM includes all kinds of active ingredients, with the characteristics of low toxicity, or low medicine waste, and it has the effects of resisting bacteria, removing inflammation, and strengthening the immunity, and the drug resistance cannot be obtained by the bacteria easily (Wang et al., 2009). More importantly, TCM-based therapies (including traditional Chinese medicine, acupuncture, and physiotherapy) have been found to be effective in promoting the recovery of gastrointestinal function in both animal experiments and clinical studies (Nishimura et al., 2001; Yin et al., 2009; Ge et al., 2011). China is rich of herbal medicinal resources; therefore it is significant to carry out researches on diseases with the compound CHM rather than the antibiotic.

Clinical well confirmed cases with improved drug efficacy and/or reduce, drug-induced toxicity when combined with herbs (Suksomboon et al., 2011; Wang et al., 2012). COL is a compound of traditional CHM, consists of Rhizoma Atractylodis, Cortex Magnoliae Officinalis, Rhizoma Coptidis, Pericarpium Citri Reticulatae, Semen Myristicae, Fructus Mume, Fructus Psoraleae, Poria cocos and Semen Lablab Album. All these crude drugs are integrated in COL with enhanced functions. In this study, the active ingredients of Berberine hydrochloride, Magnolol and Honokiol in the COL were detected using HPLC. And the other ingredients were not detectable, because the low content of ingredients and its' complexity of the CHM.

Serotonin (5-HT), has an influence on the sensory function in the gastrointestinal (GI), tract (Kim and Camilleri, 2000). The effect can occur because there are a number of different 5-HT receptor subtypes within the body. Among these receptor subtypes, the 5-HT 4 receptor is known to mediate peristaltic reflexes (Grider et al., 1998). Higher concentration of COL significantly decreased the number and the area under the curve of peristaltic waves in organ baths in this study. A possibility is that there may be the desensitization of 5-HT4 receptors located on the sensory neurons with the presence of higher concentration of COL. The higher concentrations of COL have a direct relaxant effect on the smooth muscle could be another explanation for the result of this study, since muscle tone is important not only for initiation but also for maintenance of peristalsis (Spencer et al., 2001).

A randomized clinical trial of COL showed a statistically significant therapeutic effect and better than antibiotics (Ofloxacin and Norfloxacin) for treatment of piglet diarrhea in our research. The results were agree to COL can inhibit the curve of peristaltic waves in organ baths in vitro trial.

In summary, COL can possibly inhibit the curve of peristaltic waves in vitro; and clinical trial of COL showed a statistically significant therapeutic effect in vivo. However, the ingredients, pharmacokinetics, and specific signaling pathways of COL need to be further studied.

\section{Acknowledgements}

This project was supported by the National Key Technology Research and Development Program of the Ministry of Science and Technology of China (2012BAD12B03-04).

\section{References}

1. Chan, L.W., Cheah, E.L., Saw, C.L., Weng, W. and Heng, P.W. (2008). Antimicrobial and antioxidant activities of Cortex Magnoliae Officinalis and some other medicinal plants commonly used in South-East Asia. Chin. Med., 3: 15.

2. Chen, Q., Li, Y. and Chen, Z. (2012). Separation, identification and quantification of active constituents in Fructus Psoraleae by highperformance liquid chromatography with UV, ion trap mass spectrometry and electrochemical detection. J. Pharmaceut. Anal., 2: 143-151.

3. Chinese Pharmacopoeia Commission. (2010). Chinese Pharmacopoeia, 2010 ed. China Medical Science Press, Beijing.

4. Chou, P.B., Morse, C.A. and Xu, H. (2008). A controlled trial of Chinese herbal medicine for premenstrual syndrome. J. Psychosom. Obst. Gyn., 29: 185-192, 2008.

5. Dewey, C.E., Wittum, T.E., Hurd, H.S., Dargatz, D.A. and Hill, G.W. (1995). Herd- and litter-level factors associated with the incidence of diarrhea morbidity and mortality in piglets 4-14 days of age. Swine health prod., 3: 105-112.

6. Dou, S.S., Zhu, S.L., Dai, W.X., Zhang, W.D., Zhang, Y. and Liu, R.H. (2010). Qualitative and quantitative analysis for the quality control of Rhizoma Coptidis by HPLC-DAD and HPLC-ESI-MS. Chem. Res. Chinese U., 26: 735-741.

7. Ge, H.X., Xu, C.P., Chu, L.L., Yang, X.Y. and Liu K. (2011). Effects of injecting traditional Chinese herbs via nasojejunal tube on gastrointestinal recovery following esophageal cancer surgery. J. Nursi. Sci., 26: 4-6.

8. Gong, J.H., Xu, X.H., Wang, J.M., Du, S.L. and Yang, Y. (2010). Experiment study on polysaccharide in Dolichos lablab L. on antioxidant and immune of polysaccharide in normal mice. Sci. Technol. Food Ind., 31: 337-338.

9. Grider, J.R., Foxx-Orenstein, A.E. and Jin, J.G. (1998). 5-Hydroxytryptamine4 receptor agonists initiate the peristaltic reflex in human, rat, and guinea pig intestine. Gastroenterology 115: 370-380.

10. Heinemann, A., Shahbazian, A., Barthó, L. and Holzer P. (1999). Different receptors mediating the inhibitory action of exogenous ATP and endogenously released purines on guinea-pig intestinal peristalsis. Brit. J. Pharmacol., 128: 313-320.

11. Herbert, M.K., Weis, R., Holzer, P. and Roewer, N. (2005). Peristalsis in the Guinea pig small intestine in vitro is impaired by acetaminophen but not aspirin and dipyrone. Anesth. Analg., 100: 120-127.

12. Ji, S.W., Park, H., Chung, J.P., Lee, S.I. and Lee, Y.H. (2004). Effects of tegaserod on ileal peristalsis of guinea pig in vitro. J. Pharmacol. Sci., 94: $144-152$

13. Jiao, Z.L. (2004). Exploitation and research of traditional Chinese medicine compound prescriptions. Shaanxi J. Tradit. Chin. Med., 25: 357359.

14. Jung, K., Kang, B.K., Lee, C.S. and Song, D.S. (2008). Impact of porcine group A rotavirus co-infection on porcine epidemic diarrhea virus pathogenicity in piglets. Res. Vet. Sci., 84: 502-506.

15. Karki, R., Jeon, E.R. and Kim, D.W. (2012). Magnoliae Cortex inhibits intimal thickening of carotid artery through modulation of proliferation and migration of vascular smooth muscle cells. Food Chem. Toxicol., 50: 634-640. 
http://dx.doi.org/10.4314/ajtcam.v11i1.22

16. Kim, D.Y. and Camilleri, M. (2000). Serotonin: A mediator of the brain-gut connection. Am. J. Gastroenterol., 95: $2698-2709$.

17. Kong, W.J., Zhao, Y.L., Xiao, X.H., Wang, J.B., Li, H.B., Li, Z.L., Jin, C. and Liu, Y. (2009). Spectrum-effect relationships between ultra performance liquid chromatography fingerprints and anti-bacterial activities of Rhizoma coptidis. Anal. Chim. Acta, 634: $279-285$.

18. Li, L.J., Li, Y.R. and Zhang, G.Z. (2007). Causes, symptoms and treatment technic of cow with mastitis. J. Anim. Sci. Vet. Med., 26, 99-101.

19. Li, T. and Peng, T. (2013). Traditional Chinese herbal medicine as a source of molecules with antiviral activity. Antivir. Res., 97: 1-9.

20. Lu, M.K., Cheng, J.J., Lin, C.Y. and Chang, C.C. (2010). Purification, structural elucidation, and anti-inflammatory effect of a water-soluble 1,6-branched 1,3- $\alpha$-D-galactan from cultured mycelia of Poria cocos. Food Chem., 118: 349-356.

21. Nakajima, S., Fujita, K., Inoue, Y., Nishio, M. and Seto, Y. (2006). Effect of the folk remedy, Bainiku-ekisu, a concentrate of Prunus mume juice, on Helicobacter pylori infection in humans. Helicobacter, 11: 589-591.

22. Nishimura, N., Naora, K., Hirano, H. and Iwamoto, K. (2001). Effects of sho-saiko-to (xiao chai hu tang), a Chinese traditional medicine, on the gastric function and absorption of tolbutamide in rats. J. Pharmaceut. Soc. Japan, 121: 153-159.

23. Prieto, J.M., Recio, M.C., Giner, R.M., Máñez, S., Giner-Larza, E.M. and Ríos, J.L. (2003). Influence of traditional Chinese antiinflammatory medicinal plants on leukocyte and platelet functions. J. Pharm. Pharmacol., 55: 1275-1282.

24. Shi, X., Lu, X.G., Zhan, L.B., Qi, X., Liang, L.N., Hu, S.Y., Yan, Y., Zhao, S.Y., Sui, H. and Zhang, F.L. (2011). The effects of the Chinese medicine $\mathrm{ZiBu} \mathrm{PiYin}$ recipe on the hippocampus in a rat model of diabetes-associated cognitive decline: a proteomic analysis. Diabetologia, 54: $1888-1899$.

25. Spencer, N.J., Smith, C.B. and Smith, T.K. (2001). Role of muscle tone in peristalsis in the guinea-pig small intestine. J. Physiol.-London, 530: $295-306$.

26. Suksomboon, N., Poolsup, N., Boonkaew, S. and Suthisisang, C.C. (2011). Meta-analysis of the effect of herbal supplement on glycemic control in type 2 diabetes. J. Ethnopharmacol., 137: 1328-1333.

27. Wang, C.Z., Calway, T. and Yuan, C.S. (2012). Herbal medicines as adjuvants for cancer therapeutics. Am. J. Chinese Med., 40: 657-669.

28. Wang, G.X., Li, R. and Zang, X.Y. (2009). Pharmacokinetics of two ingredients of the compound Chinese herbal medicine transdermal preparation in cows. Agr. Sci. China, 8: 1138-1142.

29. Xu, J. and Yang, Y. (2009). Traditional Chinese medicine in the Chinese health care system. Health Policy, 90: 133-139.

30. Yin, S.H., Du, Y.Q. and Liu, B. (2009). Clinical study on acupuncture combined with medication in restoration of gastrointestinal functions for postoperative patients with gastric cancer. Chinese Acupunct. Moxib., 29: 459-462.

31. Zhu, X.Y., Duan, M.L., Mao, S., Liu, F.H. and Xu, J.Q. (2007). Effect of Atractylis oil on proliferation of mouse splenic lymphocytes in vitro. J. Beijing Univ. Agr., 22: 38-40.

32. Zuo, G.Y., Li, Y., Han, J., Wang, G.C., Zhang, Y.L. and Bian, Z.Q. (2012). Antibacterial and synergy of berberines with antibacterial agents against clinical multi-drug resistant isolates of methicillin-resistant Staphylococcus aureus (MRSA). Molecules, 17: 10322-10330. 